\title{
Electrochemistry of 2,2'-Bipyridine Complexes of Cobalt in the Presence of Acrylonitrile
}

\author{
Shlomo Margel, Wayne Smith, and Fred C. Anson* \\ Arthur Amos Noyes Laboratory, California Institute of Technology, Pasadena, California 91125
}

\begin{abstract}
The previously claimed (1) catalysis of the electroreduction of acrylonitrile by means of a complex of Co(I) and $2,2^{\prime}$-bipyridine is shown to be erroneous. The "catalytic currents" result instead from the two-electron reduction of a mixed complex of $\mathrm{Co}(\mathrm{I})$ acrylonitrile and $2,2^{\prime}$-bipyridine. The equilibrium and forward rate constants for the formation of the mixed complex have been estimated and its spectrum is given. The behavior of a number of other vinyl monomers, which mimic acrylonitrile, is described.
\end{abstract}

Some time ago Tanaka and Sato described experiments (1) in which they claimed to have shown that a low valent complex of cobalt with $2,2^{\prime}$-bipyridine, generated electrochemically in acetonitrile as solvent, was an effective catalyst for the electrochemical reduction of acrylonitrile. We were intrigued by this report for three reasons: (i) The claimed catalysis was very notable ( $E_{1 / 2}$ for the wave attributed to acrylonitrile reduction is shifted from -2.3 to $-1.3 \mathrm{~V} v s$. $\mathrm{SCE}$ ); (ii) the reduction of acrylonitrile is a reaction of considerable industrial importance; and (iii) the catalytic mechanism was speculated to involve the adsorption of a low valent complex on the surface of the mercury electrode. We have therefore examined this system in more detail at both mercury and platinum electrodes by means of controlled potential electrolysis, cyclic voltammetry, and polarography. Contrary to the previous report (1) we find that the cobalt-2,2'bipyridine complexes do not function as catalysts for the reduction of acrylonitrile. The increase in current that results when both reactants are present arises instead from the reduction of a complex containing bipyridine, acrylonitrile, and cobalt(I) to a new complex containing cobalt in the $(-I)$ oxidation state. Several other vinyl monomers which form complexes with cobalt (I), e.g., 2,2'-bipyridine, also facilitate the reduction to cobalt $(-\mathrm{I})$. This report summarizes the experimental evidence which has led us to these conclusions.

\section{Experimental}

Apparatus.-Polarograms were obtained with a Princeton Applied Research (PAR) Model 174 polarographic analyzer and recorded with a Hewlett-Packard Model $7004 \mathrm{X}-\mathrm{Y}$ recorder. Cyclic voltammograms were obtained by means of a PAR Model 173 potentiostat driven by a conventional signal generator. The voltammograms were recorded with the $X-Y$ recorder or by photographing the screen of a Tektronix 564 oscilloscope. Controlled potential coulometry was conducted with the PAR Model 173 potentiostat equipped with a Model 179 digital coulometer. Gas chromatographic analyses for acrylonitrile in acetonitrile were obtained with a Hewlett-Packard Model 5830 A gas chromatograph with an $18 \mathrm{ft}$ column containing Carbowax $20 \mathrm{M}$ on Chromosorb W. Spectra were recorded with a Cary 11 spectrophotometer using cuvettes capped with rubber septums which were deoxygenated by purging with argon.

Measurements were conducted in a three-compartment cell. The reference electrode was a silver wire immersed in $0.1 \mathrm{M} \mathrm{AgNO}_{3}$ in acetonitrile which was double isolated by fritted glass disks from the main cell compartment. The potential of this reference electrode was $392 \mathrm{mV}$ more positive than an aqueous SCE when both were immersed in $0.01 \mathrm{M}$ aqueous

* Electrochemical Society Active Member.

Key words: catalysis, mixed complexes, vinyl monomers.
$\mathrm{KNO}_{3}$. All potentials are given with respect to the $\mathrm{Ag} / 0.1 \mathrm{MI} \mathrm{AgNO}_{3}$ reference electrode.

The platinum indicator electrode was a platinum wire (diameter $=0.076 \mathrm{~cm}$ ) sealed in soft glass and cut and polished to expose a $0.045 \mathrm{~cm}^{2}$ disk flush with the glass surface. The working electrode for the controlled potential electrolyses was a cylindrical platinum gauze electrode supported with stout platinum wire.

Solutions were deoxygenated with prepurified argon which was passed successively through an aqueous chromous chloride solution, purified acetonitrile, and a calcium chloride drying tower before entering the test solution.

Materials.-Polarographic grade tetraethylammonium perchlorate (TEAP) (Southwestern Analytical Company) was used as supporting electrolyte without additional purification. Spectroquality acetonitrile was stirred over $\mathrm{CaH}_{2}$ for $24 \mathrm{hr}$, distilled under reduced pressure, and stored under argon.

$\mathrm{Co}(\text { bipy })_{3}\left(\mathrm{ClO}_{4}\right)_{3}$ and $\mathrm{Co}(\text { bipy })_{3}\left(\mathrm{ClO}_{4}\right)_{2}$ (bipy $\equiv$ 2,2 -bipyridine) were prepared by standard methods (2), $\mathrm{Co}$ (phen) ${ }_{3}\left(\mathrm{ClO}_{4}\right)_{2}$ (phen $\equiv 1,10$-phenanthroline) was prepared by mixing a slight excess of 1,10-phenanthroline monohydrate with $\mathrm{CoCl}_{2} \cdot 6 \mathrm{H}_{2} \mathrm{O}$ in ethanol in the absence of air. Addition of a concentrated aqueous solution of $\mathrm{NaClO}_{4}$ followed by cooling to $0^{\circ} \mathrm{C}$ produced the desired solid. Ethyl cinnamate, cinnamonitrile, and 4-vinyl pyridine were distilled before use. Vinyl monomers used as received included ethyl acrylate, methyl methacrylate, styrene, and methacrylonitrile.

Preparation and properties of [Co(bipy) $\left.{ }_{2} \mathrm{CH}_{2} \mathrm{CHCN}\right]-$ $\mathrm{ClO}_{4}$.- Solid $\mathrm{Co}$ (bipy) ${ }_{3} \mathrm{ClO}_{4}$ has been isolated by reduction of $\mathrm{Co}$ (bipy) $3^{3+}$ with $\mathrm{Na}(\mathrm{Hg})$ (3) or $\mathrm{NaBH}_{4}$ 4) followed by precipitation with excess perchlorate. To obtain the corresponding acrylonitrile complex 100 $\mathrm{mg}$ of $\mathrm{Co}$ (bipy) ${ }_{3}\left(\mathrm{ClO}_{4}\right)_{2}$ was dissolved in $20 \mathrm{ml}$ of a 1:3 mixture of water and ethanol containing 200 $\mathrm{mg}$ of acrylonitrile. The mixture was freed of oxygen and all subsequent steps were conducted in an atmosphere of argon. Addition of $2 \mathrm{ml}$ of a $0.7 \mathrm{M}$ solution of $\mathrm{NaBH}_{4}$ in water produced a deep purple solution from which a black solid was precipitated by adding a large excess of $\mathrm{NaClO}_{4}$. The solid was filtered, washed with oxygen-free water and ether, and dried at room temperature under vacuum. Elemental analysis of the solid (percentages): $\mathrm{C}, 49.0 ; \mathrm{H}, 3.5 ; \mathrm{N}, 12.0 ; \mathrm{Co}, 11.9$; $\mathrm{Cl}, 7.2$. Calculated for $\mathrm{Co}$ (bipy) ${ }_{2}\left(\mathrm{CH}_{2} \mathrm{CHCN}\right) \mathrm{ClO}_{4}: \mathrm{C}$, $52.8 ; \mathrm{H}, 3.6 ; \mathrm{N}, 13.3 ; \mathrm{Co}, 11.3 ; \mathrm{Cl}, 6.8$.

The black solid is oxidized much more slowly by oxygen than is $\mathrm{Co}$ (bipy) ${ }_{3} \mathrm{ClO}_{4}$. The infrared spectrum of the solid (Nujol mull) shows a band at $2210 \mathrm{~cm}^{-1}$ (carbon-nitrogen stretch) which is not far removed from the same band in free acrylonitrile, indicating that the nitrile group is not directly involved in the bonding to the cobalt(I). The acrylonitrile-cobalt(I) bond is most likely centered on the double bond. 


\section{Results}

Polarography: Comparison with the results of Tanaka and Sato (1).-In agreement with Ref. (1), we observed four reduction waves for $\mathrm{Co}$ (bipy) $3_{3}^{3+}$ corresponding to the successive formation of complexes containing cobalt in the oxidation states (II), (I), and ( - I) followed by the reduction of liberated 2,2'-bipyridine. The half-wave potentials also agreed with those listed in Ref. (1). The addition of acrylonitrile to solutions of Co (bipy) $3^{3+}$ resulted in the "catalytic wave" described by Tanaka and Sato (1) but the properties of this wave are very sensitive to the concentration of the supporting electrolyte. With the rather low supporting electrolyte concentration employed in Ref. (1) (0.05M tetraethylammonium perchlorate), the "catalytic wave" exhibited the properties described by Tanaka and Sato, i.e., the limiting current of the catalytic wave was approximately proportional to the acrylonitrile concentration up to concentrations as large as 5 times the concentration of the cobalt complex. However, if the concentration of supporting electrolyte is increased, this behavior changes: The magnitude of the catalytic wave is no longer proportional to the concentration of acrylonitrile. Instead it tends toward a limiting value close to that of the wave corresponding to the reduction of $\mathrm{Co}(\mathrm{I})$ to $\mathrm{Co}(-\mathrm{I})$ in the absence of acrylonitrile (Fig. 1). Even when neat acrylonitrile is used in place of acetonitrile as the solvent the magnitude of the limiting current of the catalytic wave remains about the same (Fig. 1).

In agreement with Tanaka and Sato (1) we observed that the addition of free $2,2^{\prime}$-bipyridine to solutions of Co (bipy) $3^{3+}$ causes no shift in the half-wave potentials of the waves corresponding to the reduction of $\mathrm{Co}$ (III) to $\mathrm{Co}$ (II) and of $\mathrm{Co}$ (II) to $\mathrm{Co}$ (I) while the wave for the reduction of $\mathrm{Co}(\mathrm{I})$ to $\mathrm{Co}(-\mathrm{I})$ shifts to more negative potentials. In the presence of acrylonitrile the value of $E_{1 / 2}$ for the reduction of Co (II) to Co (I) does respond to the addition of 2,2 -bipyridine until its concentration is increased sufficiently to cause the value of $E_{1 / 2}$ to match its value in the absence of acrylonitrile, whereupon further additions of 2,2'-bipyridine are without effect (Table I).

Spectral observations.-The intensely blue complex formed by reducing cobalt(II) in the presence of 2,2 bipyridine has a visible absorption spectrum with a maximum at $600 \mathrm{~nm}$ (5). Since the cobalt(II)-bipy complexes show essentially no absorption in this region of the spectrum, it proved possible to utilize the absorbance at $600 \mathrm{~nm}$ to determine the number of mole-cules of $2,2^{\prime}$-bipyridine coordinated to cobalt in the Co(I) complex by means of the method of continuous variations (6). Figure 2 shows a plot of the absorbance at $600 \mathrm{~nm}$ as a function of the ratio of 2,2'-bipyridine

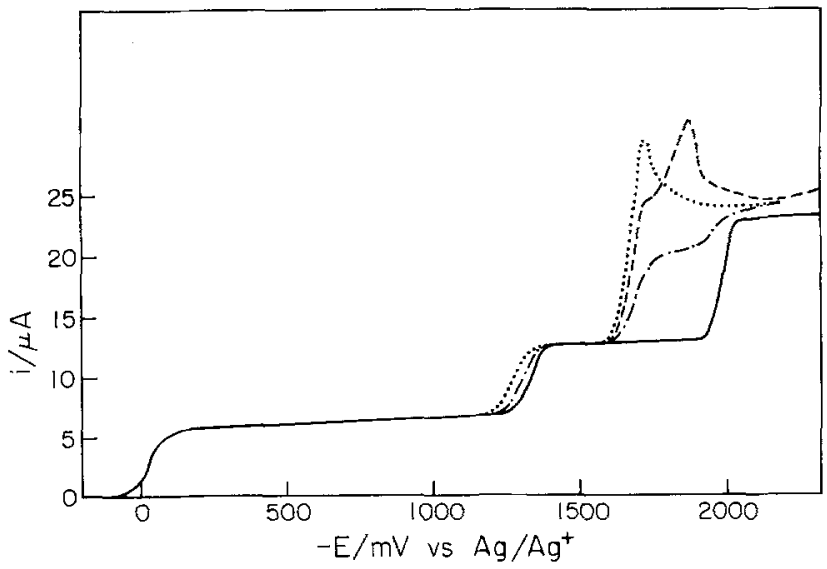

Fig. 1. D-C polarograms for $1 \mathrm{mM} \mathrm{Co(bipy)} 3^{3+}$ in acetonitrile: (-) no acrylonitrile; (.-..-) I $\mathrm{mM}$ acrylonitrile; (- - ) $2 \mathrm{mM}$ acrylonitrile; $(\cdots)$ ) pure acrylonitrile as solvent. Supporting electrolyte: 0.1M TEAP. Capillary characteristics: drop time $1 \mathrm{sec}$, mercury flow rate $-1.26 \mathrm{mg} \mathrm{sec}-1$.
Table I. Half-wave potentials for the reduction of $\mathrm{Co}(11)$ to $\mathrm{Co}(\mathrm{I})$ in acetonitrile solutions containing 2,2'-bipyridine and acrylonitrile. All solutions contained $0.6 \mathrm{mM} \mathrm{Co}(\text { bipy })_{3}\left(\mathrm{ClO}_{4}\right)_{2}$ and $0.1 \mathrm{M}$ TEAP

\begin{tabular}{ccc}
$\begin{array}{c}\text { Conc of acry- } \\
\text { lonitrile (mM) }\end{array}$ & $\begin{array}{c}\text { Added bipy } \\
\text { conc (mM) }\end{array}$ & $\begin{array}{c}-E_{1 / 2} \text { (V Vs. } \\
\text { Ag/0.1M AgNÖ) }\end{array}$ \\
\hline 0 & 0 & 1.340 \\
0.8 & 0 & 1.336 \\
1.6 & 0 & 1.327 \\
2.4 & 0 & 1.324 \\
4.0 & 0 & 1.320 \\
6.0 & 0 & 1.318 \\
14.0 & 0 & 1.315 \\
22.0 & 0 & 1.318 \\
22.0 & 1.2 & 1.320 \\
22.0 & 2.4 & 1.323 \\
22.0 & 3.6 & 1.325 \\
22.0 & 6.0 & 1.338 \\
$\mathbf{2 2 . 0}$ & 14.0 &
\end{tabular}

to cobalt in solutions prepared by mixing $\mathrm{Co}\left(\mathrm{ClO}_{4}\right)_{2}$ and the ligand in oxygen-free methanol and adding a slight excess of $\mathrm{NaBH}_{4}$ dissolved in oxygen-free methanol. The two straight lines drawn through the data points intersect at a ratio of 2,2 -bipyridine to cobalt of 2.95 indicating that the cobalt (I) complex present is predominately $\mathrm{Co}$ (bipy) ${ }_{3}{ }^{+}$.

The spectral changes accompanying the conversion of $\mathrm{Co}(\mathrm{bipy})_{3}{ }^{+}$to the mixed complex containing acrylonitrile are shown in Fig. 3. It did not prove possible to obtain reliable estimates of the relative concentrations of complexes present from the spectra, but the large spectral changes make it clear that there is substantial complexation of acrylonitrile by cobalt(I). Tanaka and Sato (1) reached the opposite conclusion, but they did not examine the visible spectra of their solutions.

Cyclic voltammetry.-Our observation that the polarographic wave which Tanaka and Sato attributed to the catalyzed reduction of acrylonitrile had a magnitude that was quite sensitive to the ionic strength of the supporting electrolyte suggested that the wave might have been exalted by polarographic streaming maxima in the dilute supporting electrolyte employed in Ref. (1). The system was therefore examined by cyclic voltammetry with a platinum electrode replacing the dropping mercury electrode. The cyclic voltammograms for Co(bipy) $3^{3+}$ in the absence of acrylonitrile exhibit the same three waves [Co(III) $\rightarrow \mathrm{Co}$ (II), $\mathrm{Co}(\mathrm{II}) \rightarrow \mathrm{Co}(\mathrm{I}), \mathrm{Co}(\mathrm{I}) \rightarrow \mathrm{Co}(-\mathrm{I})]$ that were observed in the polarographic experiments. The first two waves exhibit reversible behavior at all scan rates with peak

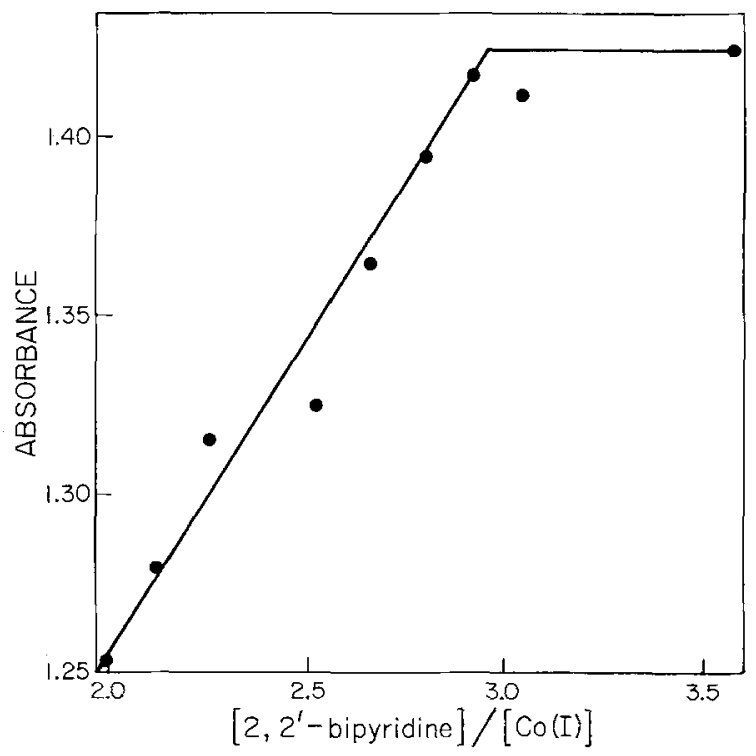

Fig. 2. Absorbance at $600 \mathrm{~nm}$ vs. the ratio of $2,2^{\prime}$-bipyridine to $\mathrm{Co}(\mathrm{I})$ in methanol. 


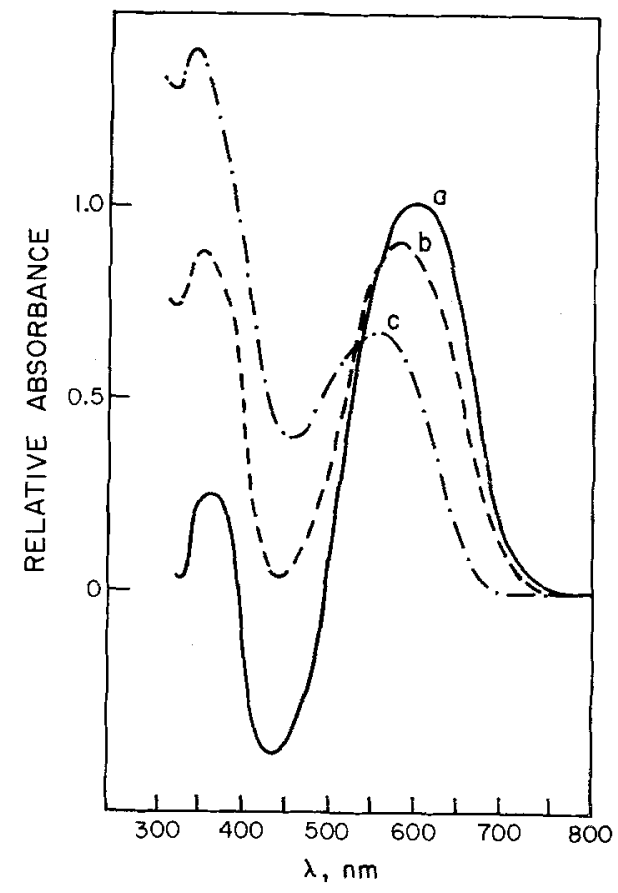

Fig. 3. Effect of acrylonitrile on the absorption spectrum of $0.1 \mathrm{mM} \mathrm{Co}(1)$ in a methanol solution containing $0.9 \mathrm{mM} \mathrm{2,2}$-bipyridine: $(\longrightarrow$ no acrylonitrile; (- -$) 0.2 \mathrm{mM}$ acrylonitrile (-.-C) $1.6 \mathrm{mM}$ acrylonitrile. The $\mathrm{Co}(1)$ was obtained by reduction of $\mathrm{Co}(\mathrm{II})$ with a slight excess of $\mathrm{NaBH}_{4}$.

potential separations of $c a .60 \mathrm{mV}$ and no dependence of peak potentials on scan rate or the addition of $2,2^{\prime}$ bipyridine. The third wave exhibits reversible behavior at moderate scan rates ( $1 \mathrm{~V} \mathrm{sec}-1$ ) with peak potentials and anodic-cathodic peak potential separations that depend on the concentration of added 2,2'-bipyridine. Figure 4 shows the dependence of the average of the anodic and cathodic peak potentials of all three waves on the concentration of 2,2'-bipyridine. The slope of the line drawn through the points for the $\mathrm{Co}(\mathrm{I})-\mathrm{to}_{\mathrm{O}} \mathrm{Co}(-\mathrm{I})$ wave is $25 \mathrm{mV} /$ decade which indicates that one molecule of $2,2^{\prime}-$ bipyridine is lost when the Co(I) complex is reduced to Co $(-\mathrm{I})$.

Figure 5 contains a representative set of voltammograms for the second and third reduction steps in
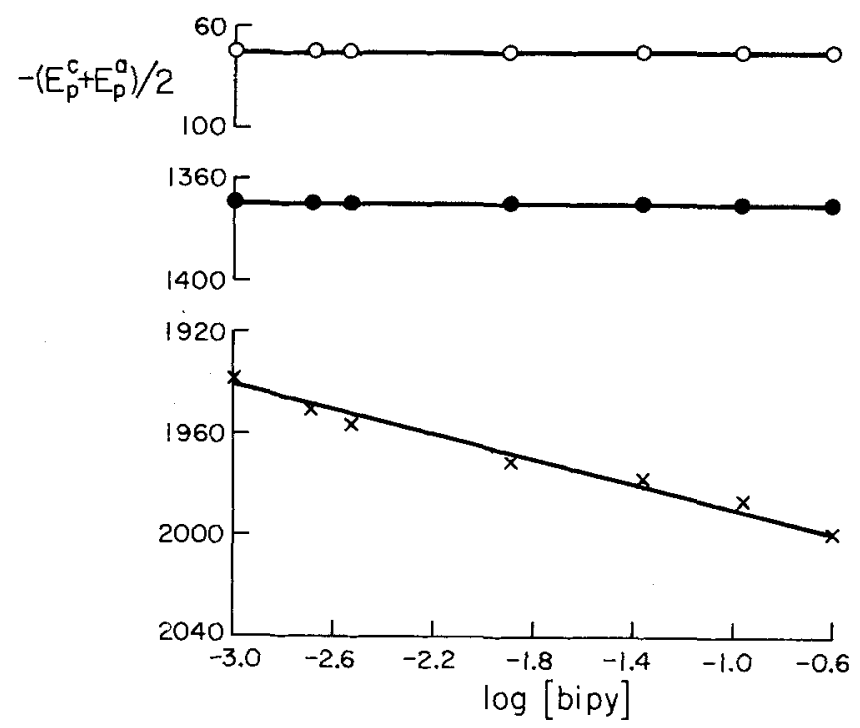

Fig. 4. Average of cathodic and anodic peak potentials for cyclic voltammograms: $(O), \mathrm{C}_{0}(I I I) \rightleftharpoons \mathrm{Co}_{0}(I I) ;(\bullet) . \mathrm{C}_{0}(I I) \rightleftharpoons \mathrm{Co}_{0}(\mathrm{l}) ;$ $(X), \mathrm{Co}(\mathrm{I}) \rightleftharpoons \mathrm{Co}_{\mathrm{O}}(-\mathrm{I})$ in acetonitrile solutions of 2,2 -bipyridine. Concentration of cobolt: $1 \mathrm{mM}$. Supporting electrolyte: $0.1 \mathrm{M}$ TEAP. Scan rate: $1 \vee \sec ^{-1}$.

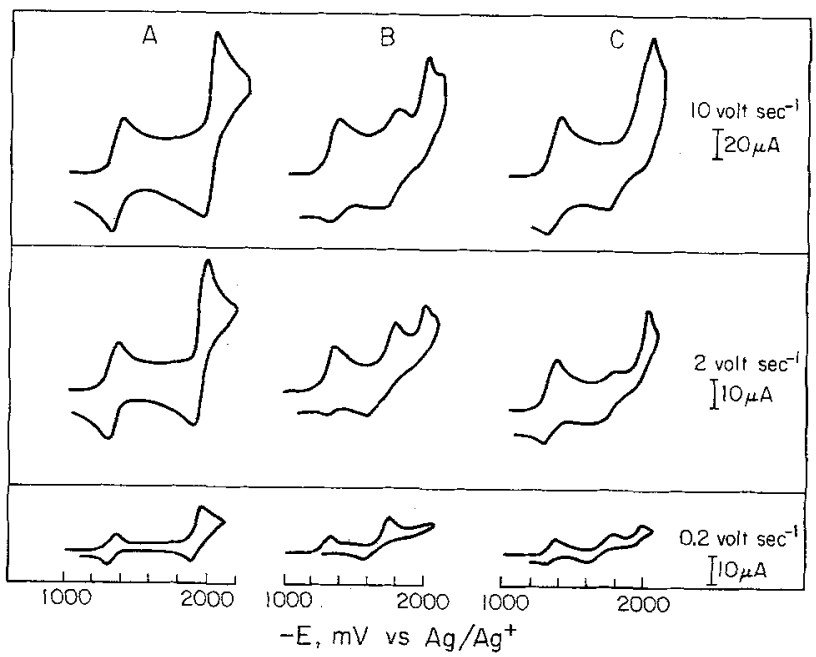

Fig. 5. Cyclic voltammograms for $\mathrm{Co}(\text { bipy })_{3}\left(\mathrm{ClO}_{4}\right)_{2}$ in acetonitrile: A, no acrylonitrile present; $B, 2.5 \mathrm{mM}$ acrylonitrile present; C, 2.5 $\mathrm{mM}$ acrylonitrile and $2.0 \mathrm{mM} \mathrm{2,2}$-bipyridine present. Supporting electrolyte: $0.1 \mathrm{M}$ TEAP. Platinum microelectrode: $0.045 \mathrm{~cm}^{2}$.

the absence and presence of acrylonitrile. As acrylonitrile is added to the solution of Co(bipy) $3^{3+}$ a new wave appears (Fig. 5B), but its magnitude never exceeds that of the wave corresponding to the reduction of $\mathrm{Co}(\mathrm{I})$ to $\mathrm{Co}(-\mathrm{I})$ in the absence of acrylonitrile. This wave merely diminishes at the same rate as the new wave grows. Both waves correspond to the two-electron reduction of cobalt(I) without any apparent reduction of acrylonitrile.

The relative magnitude of the two cyclic voltammetric waves depends on the rate of potential scan: The less negative wave is suppressed and the more negative wave is enhanced the higher the scan rate. The less negative wave is reversible at high scan rates but becomes progressively less so as the scan rate is diminished. The wave can also be suppressed or eliminated by addition of $2,2^{\prime}$-bipyriaine to solutions containing Co (bipy) $3^{3+}$ and acrylonitrile (Fig. 5C). The behavior is consistent with the presence of a sluggishly established equilibrium as indicated in reaction [1]

\section{$\mathrm{Co}(\text { bipy })_{3}{ }^{+}+\mathrm{CH}_{2} \mathrm{CHCN}$}

$$
\underset{k_{\mathrm{b}}}{\stackrel{k_{\mathrm{f}}}{\rightleftharpoons}}\left[\mathrm{Co}(\text { bipy })_{2} \mathrm{CH}_{2} \mathrm{CHCN}\right]++ \text { bipy }
$$

The new wave resulting from the addition of acrylonitrile can then be understood as the reduction of the mixed $\mathrm{Co}(\mathrm{I})$ complex, [Co (bipy) $\left.{ }_{2} \mathrm{CH}_{2} \mathrm{CHCN}\right]^{+}$, to the $\mathrm{Co}(-\mathrm{I})$ state.

An estimate of the equilibrium constant for reaction [1] was obtained by preparing solutions of Co (bipy) $3^{3+}$ containing various concentrations of acrylonitrile and $2,2^{\prime}$-bipyridine and adjusting the potential of a platinum indicator electrode to $-1400 \mathrm{mV}$ [where the cobalt (III) complex was reduced to a mixture of the two cobalt(I) complexes] for $60 \mathrm{sec}$ to allow the equilibrium in reaction [1] to be established. The electrode potential was then scanned toward more negative values and the peak currents for the two waves corresponding to the reduction of $\mathrm{Co}(\mathrm{I})$ to $\mathrm{Co}(-\mathrm{I})$ were measured. At scan rates of $5 \mathrm{~V} \mathrm{sec}^{-1}$ or greater the ratio of the two peak currents became essentially independent of scan rate and thus provided a direct measure of the equilibrium concentrations of $\mathrm{Co}(\text { bipy })_{3}+$ and $[\mathrm{Co}-$ (bipy) $\left.{ }_{2} \mathrm{CH}_{2} \mathrm{CHCN}\right]^{+}$. Table II summarizes the results obtained from a series of such measurements and the resulting values of the equilibrium constant for reaction [1]. The reasonable constancy of the equilibrium constants obtained support the stoichiometry indicated in reaction [1], i.e., one molecule of 2,2-bipyridine is replaced by one molecule of acrylonitrile to form the more easily reduced complex. 
Table II. Equilibrium constant for reaction [1], $K_{1}$, evaluaied from voltammetric peak current ratios

\begin{tabular}{|c|c|c|c|c|}
\hline $\begin{array}{l}\text { Scan rate } \\
\text { (V sec-1) }\end{array}$ & $\begin{array}{l}\text { Cone of } \\
2,2^{\prime}-\text { bipy- } \\
\text { ridine } \\
\text { (mM) }\end{array}$ & $\begin{array}{c}\text { Cone of } \\
\text { acry- } \\
\text { lonitrile } \\
\text { (mM) }\end{array}$ & $\underset{\text { current }}{\text { Patiof }}$ & $\underset{\text { (calc) }}{K_{1}}$ \\
\hline \multirow[t]{2}{*}{$\begin{array}{r}5 \\
10 \\
5 \\
10 \\
5 \\
10 \\
20 \\
5 \\
10\end{array}$} & $\begin{array}{r}5.0 \\
5.0 \\
12.5 \\
12.5 \\
2.5 \\
2.5 \\
2.5 \\
5.0 \\
5.0\end{array}$ & $\begin{array}{r}5.0 \\
5.0 \\
5.0 \\
5.0 \\
5.0 \\
5.0 \\
5.0 \\
10.0 \\
10.0\end{array}$ & $\begin{array}{l}1.00 \\
1.05 \\
0.47 \\
0.52 \\
0.22 \\
0.27 \\
0.25 \\
2.07 \\
2.0\end{array}$ & $\begin{array}{l}1.0 \\
1.1 \\
1.2 \\
1.3 \\
1.1 \\
1.3 \\
1.3 \\
1.0 \\
1.0\end{array}$ \\
\hline & & & \multicolumn{2}{|c|}{ Average: 1.1} \\
\hline
\end{tabular}

* The concentration of Co (bipy) $\mathrm{s}^{3+}$ was $0.5 \mathrm{mM}$

$\uparrow$ The ratio is of the peak current corresponding to the reduction of the acrylonitrile complex to that for the reduction of Co(bipy) $3^{+}$. A platinum microelectrode $\left(0.045 \mathrm{~cm}^{2}\right)$ was employed.

Kinetics of reaction [1].-The cyclic voltammetric behavior of the pair of waves corresponding to the reduction of $\mathrm{Co}$ (bipy) ${ }_{3}^{2+}$ and the oxidation of $\mathrm{Co}$ (bipy) $)_{3}+$ can be utilized to inspect the kinetics of reaction [1]. In the absence of acrylonitrile the cathodic and anodic peak currents for these two waves are equal, but the anodic peak current is diminished by the addition of acrylonitrile as reaction [1] proceeds from left to right (Fig. 5B). By working in the presence of excess acrylonitrile the reaction can be made pseudo first order and essentially irreversible. Under these conditions the forward rate constant for reaction [1] can be evaluated from the sweep rate dependence of the peak current ratio (7). Table III summarizes the data obtained from which an average value for $k_{\mathrm{f}}$ of $8 \times$ $10^{3} \mathrm{M}^{-1} \mathrm{sec}^{-1}$ was calculated.

Controlled potential electrolysis.-Successive electrolysis of acetonitrile solutions of $\mathrm{Co}$ (bipy) $3^{3+}$ with mercury pool or platinum gauze electrodes at potentials on the plateau of the first and then of the second polarograph waves (i.e., -100 and $-1400 \mathrm{mV}$, respectively) results in the consumption of $1 F /$ mole for each wave as expected for successive reductions to Co(bipy) $3^{2+}$ and $\mathrm{Co}$ (bipy) $3^{+}$. During the reduction to Co (bipy) $3^{+}$the solution develops the deep blue color characteristic of this complex $(3,4)$. If the electrolysis is continued at the same potential an additional faraday per mole of electricity is slowly consumed over a period of a few hours, the blue color fades, and a dark precipitate resembling metallic cobalt appears. This slow, electrolytic decomposition of the complex is diminished by the addition of excess 2,2'-bipyridine.

Acrylonitrile is without effect on the course of the controlled potential reduction of $\mathrm{Co}$ (bipy) $3^{3+}$ and $\mathrm{Co}-$ (bipy) ${ }_{3}^{2+}$. However, if sufficient acrylonitrile is present the color developed as $\mathrm{Co}(\mathrm{I})$ is produced and is

Table III. Forward rate constant for reaction [1], $k_{\mathrm{f}}$ estimated from cyclic voltammetric peak current ratios

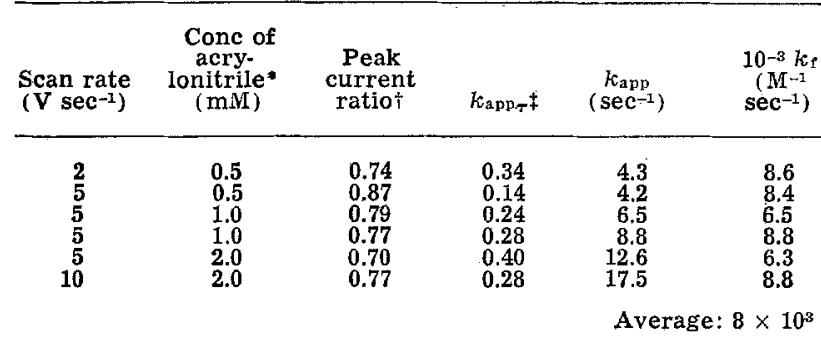

* The concentration of $\mathrm{Co}$ (bipy) ${ }_{3}\left(\mathrm{ClO}_{4}\right)_{2}$ was $0.5 \mathrm{mM}$. Supporting electrolyte: $0.1 \mathrm{M}$ TEAP.

The ratio is of the peak current for the oxidation of $\mathrm{Co}$ (bipy) $\mathrm{s}^{+}$to that for the reduction of Corbipy) $3^{2+}$

(bipy) $a^{+}$to that for the reduction of Cofbipy) $3^{2+}$ (7) The neg igibility of the reverse of reaction [1] under the experimenta conditions employed was demonstrated by the lack of significant changes in the peak current ratio when small amounts of $2,2^{\prime}$-bipyridine were added to the solutions. deep purple rather than the characteristic blue of $\mathrm{Co}-$ (bipy) ${ }_{3}^{+}$. The same color can be produced by adding acrylonitrile to a previously electrogenerated solution of $\mathrm{Co}$ (bipy) $)_{3}+$. It is apparently the color of the mixed complex, $\mathrm{Co}$ (bipy) ${ }_{2}\left(\mathrm{CH}_{2} \mathrm{CHCN}\right)+$.

Controlled potential reduction of the purple solution at a potential on the plateau of the new wave now present (Fig. 5B) results in the consumption of almost exactly two additional faradays per mole of Co and yields a brownish yellow solution. This result is independent of the excess of acrylonitrile present: The same behavior is obtained if acrylonitrile is substituted for acetonitrile as the solvent.

That no reduction of the acrylonitrile occurs during the controlled potential reduction was confirmed by gas chromatographic analysis of the solution before and after the electrolysis: Only a negligible loss of acrylonitrile was observed by the time that $2 \mathbf{F} / \mathrm{mole}$ of cobalt had been consumed and the current had decayed to its background level.

If the controlled potential electrolysis is carried out with a solution containing Co (bipy) $3^{2+}$ and acrylonitrile the total charge consumed at $-1.7 \mathrm{~V}$ is $3 \mathbf{F} / \mathrm{mole}$ of cobalt(II), as expected, but the initial current is not as large as would correspond to the simple, direct reduction of cobalt(II) to cobalt (-I). The behavior is consistent with the intervention of a slow chemical step along the electrolytic pathway. A likely candidate for such a slow step is reaction [1]. If the electrolysis is continued beyond the point at which the cobalt has been converted to $\mathrm{Co}(-\mathrm{I})$ the current falls to the background level but the concentration of acrylonitrile monitored by gas chromatography decreases slowly over a period of several hours. However, there is no detectable loss of acrylonitrile before this stage of the electrolysis. We found no evidence of acrylonitrile reduction accompanying the reduction of the cobalt

Reaction of $\mathrm{Co}(\text { bipy })_{3}+$ with vinyl monomers.-The apparent propensity for acrylonitrile to coordinate to $\mathrm{Co}(1)$ and thereby facilitate its further reduction suggested that other vinyl monomers might exhibit similar behavior. This proved to be the case for a number of vinyl monomers which all produce the same wave near $-1.7 \mathrm{~V}$ that results when acrylonitrile is added to solutions of $\mathrm{Co}$ (bipy) $3^{2+}$. The wave height in each case corresponds to the reduction of $\mathrm{Co}(\mathrm{I})$ to $\mathrm{Co}(-\mathrm{I})$. The equilibrium and forward rate constants for the formation of the assumed cobalt(I)-vinyl monomer complexes according to reaction [2]

monomer $+\mathrm{Co}(\text { bipy })_{3}+$

$$
\rightleftharpoons \mathrm{Co} \text { (bipy) }{ }_{2} \text { monomer }{ }^{+}+\text {bipy }
$$

were evaluated by the same cyclic voltammetric procedures employed with acrylonitrile and the results are given in Table IV. Note that the stability of the cobalt(I) -vinyl monomer complexes increases with the ease of reduction of the monomer itself $\left(E_{1 / 2}\right.$ values are given in Table IV).

The results that have been described can all be accommodated on the basis of the set of reaction se-

Table IV. Forward rate constants, $k_{\mathrm{f}}$. and equilibrium constants,

$K_{2}$, for reaction [2] estimated from voltammetric peak current ratios

\begin{tabular}{|c|c|c|c|}
\hline Vinyl monomer & $\begin{array}{c}k_{f}\left(\mathrm{M}^{-1}\right. \\
\left.\text { sec }^{-1}\right)\end{array}$ & $K_{2}$ & $\begin{array}{c}\text { Half-wave } \\
\text { potential of } \\
\text { the monomer, } \\
-E_{1 / 2}(\mathrm{~V})\end{array}$ \\
\hline $\begin{array}{l}\text { Ethyl cinnamate } \\
\text { Cinnamonitrile } \\
\text { Ethyl acrylate } \\
\text { Acrylonitrile } \\
\text { 4-Vinyl pyridine } \\
\text { Methacryionitrile } \\
\text { Methyl methacrylate } \\
\text { Styrene }\end{array}$ & $\begin{aligned} & 9 \times 10^{2} \\
& 4 \times 10^{2} \\
& 5 \times 10^{2} \\
& 5 \times 10^{-1} \\
& 8 \times 10^{3} \\
& 2 \\
&<10^{-1} \\
& \sim 3 \times 10^{-1}\end{aligned}$ & $\begin{array}{l}4.5 \times 10^{-8} \\
5.0 \times 10^{-2} \\
6.0 \times 10^{-2} \\
1.3 \times 10^{-5} \\
1.1 \times \\
7.0 \times 10^{-4} \\
\quad *\end{array}$ & $\begin{array}{l}2.2 \\
2.2 \\
2.5 \\
2.57 \\
2.55 \\
2.62 \\
2.63 \\
2.83\end{array}$ \\
\hline
\end{tabular}

* Too small to measure, i.e., $<10^{-5}$ 
Scheme I

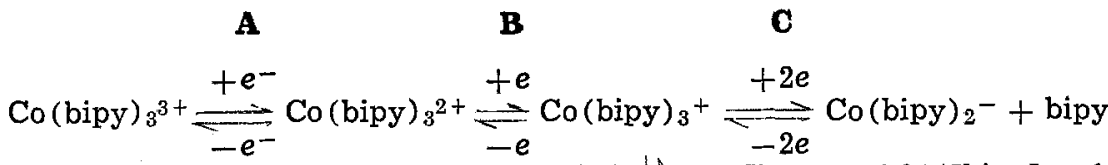

$$
\begin{aligned}
& E_{1 / 2}=-0.07 \mathrm{~V} \quad E_{1 / 2}=-1.37 \mathrm{~V} \text { |N } \quad E_{1 / 2}=-1.94\left([\mathrm{bipy}]=10^{-3 \mathrm{M})}\right. \\
& \text {-bipy + bipy D } \\
& +\mathrm{CH}_{2} \mathrm{CHCN} \sqrt{-\mathrm{CH}_{2} \mathrm{CHCN}} \\
& K_{\text {eq }}=1.1 \\
& \text { D }
\end{aligned}
$$$$
\left[\mathrm{Co}(\text { bipy })_{2} \mathrm{CH}_{2}=\mathrm{CHCN}\right]+\frac{\stackrel{\mathbf{E}}{+2 e^{-}}}{\underset{E_{1 / 2}}{\rightleftharpoons}}\left[\mathrm{Co}(\text { bipy })_{x}\left(\mathrm{CH}_{2} \mathrm{CHCN}\right)_{y}\right]
$$

quences given in Scheme I. The evidence to support the conclusion that there is no loss of coordinated 2,2'bipyridine as $\mathrm{Co}$ (bipy) $3^{3+}$ is reduced to $\mathrm{Co}$ (bipy) ${ }_{3}{ }^{+}$ is the fact that both the polarographic half-wave potentials and the cyclic voltammetric peak potentials corresponding to the reversible steps $\mathbf{A}$ and $\mathbf{B}$ in Scheme I show no dependence on the concentration of free 2,2'-bipyridine (Table I; Fig. 4). However, this does not require that the $2,2^{\prime}$-bipyridine retain its bidentate chelation of the cobalt center when the latter is reduced to the $\mathrm{Co}(\mathrm{I})$ state. The resulting $\mathrm{d}^{8}$ complex could well become five-coordinate by the breaking of one of the cobalt-bipy bonds.

Both step $\mathbf{C}$ and steps $\mathbf{D}+\mathbf{E}$ in Scheme I show halfwave and peak potentials which depend on the concentration of 2,2'-bipyridine in the way to be expected if a loss of coordinated 2,2'-bipyridine accompanied the electrode reaction. It is noteworthy that step $D$ could not be observed with the $\mathrm{Co}(\mathrm{phen})_{3}{ }^{+}$complex even in the presence of large excesses of acrylonitrile. Apparently the steric constraints imposed by the larger and more rigid 1, 10-phenanthroline ligands which cannot become monodentate as readily as can $2,2^{\prime}$-bipyridine, impedes the formation of the $\pi$-bonded acrylonitrile complex.

The composition of the product of step $\mathbf{E}$ was not definitely established. However, it is not the same as the product of step $\mathbf{C}$ because solutions resulting from the reduction of $\mathrm{Co}$ (bipy) ${ }_{3}{ }^{2+}$ by three electrons in the absence of acrylonitrile are noticeably bluer than those obtained when acrylonitrile is present. Moreover, the latter solutions can be converted to what appears to be the same blue color by the addition of excess 2,2 'bipyridine following the reduction. The $\mathrm{Co}(-\mathrm{I})$ complex may contain more than a single acrylonitrile molecule and fewer than two 2,2'-bipyridine molecules but the available data are inadequate to permit a definitive assignment of its composition.

The primary differences between the interpretations offered by Tanaka and Sato and that given in Scheme I are the lack of any reduction of acrylonitrile and the proposed formation in step $\mathbf{D}$ of a stable, mixed complex of acrylonitrile and 2,2'-bipyridine which undergoes reduction to the $\mathrm{Co}(-\mathrm{I})$ state at less negative potentials than does the $\mathrm{Co}(\text { bipy })_{3}{ }^{+}$complex. That the mixed complex has the composition given in Scheme I is supported by the spectral data, cyclic voltammetric data from which reasonably constant values for the equilibrium constant for step D were obtained (Table II), and the fact that a perchlorate salt was isolated which gave an elemental analysis that corresponded reasonably well to that calculated for [Co (bipy) ${ }_{2} \mathrm{CH}_{2}-$ $\mathrm{CHCN}] \mathrm{ClO}_{4}$.

Tanaka and Sato concluded that $\mathrm{Co}$ (bipy) ${ }_{3}{ }^{+}$and $\mathrm{CH}_{2} \mathrm{CHCN}$ do not react with each other in the bulk of solution because the height of the polarographic wave they attributed to the reduction of the product of this reaction did not increase linearly with the concentration of $\mathrm{Co}$ (bipy) ${ }_{3}{ }^{+}$. On this basis they argued that the mixed complex was formed only at the mercury elec- trode surface where it was adsorbed. As mentioned earlier, we believe Tanaka and Sato were misled by the presence of polarographic maxima under the conditions of their experiments. By employing higher supporting electrolyte concentrations or by substituting a platinum electrode for the DNE we observed wave heights that remained linearly proportional to the concentration of cobalt(I) throughout the range from 0.1 to $10 \mathrm{mM}$. We found no evidence of adsorption of $\mathrm{Co}-$ (bipy) $3^{2+}$ or $\mathrm{Co}$ (bipy) $3^{3+}$ in the cyclic voltammetric data at mercury electrodes: The cathodic and anodic peak currents for the $\mathrm{Co}$ (II)/Co(I) waves remained proportional to the square root of the scan rate and equal to each other up to scan rates of $20 \mathrm{~V} \mathrm{sec}-1$. Chronocoulometric measurements indicated some possible adsorption of $\mathrm{Co}$ (bipy) ${ }_{3}{ }^{+}$, but it was not possible to distinguish between adsorption and precipitation of the slightly soluble $\mathrm{Co}$ (bipy) ${ }_{3} \mathrm{ClO}_{4}$ on the electrode surface.

Polarographic maxima were apparently also responsible for the erroneous assertion (1) that acrylonitrile reduction is catalyzed in the presence of Co(bipy) ${ }_{3}{ }^{+}$. Limiting currents that exceed two electrons per Co(I), the sole basis for the conclusions of Tanaka and Sato, are not observed with larger supporting electrolyte concentrations or at platinum electrodes. Of course, the controlled potential electrolytic reduction of solutions containing both Co (bipy) $3^{2+}$ and acrylonitrile in which the charge consumed corresponds to precisely three electrons per Co(II) and is independent of the amount of acrylonitrile present provides the clearest proof that acrylonitrile is not reduced. Gas chromatographic monitoring of the concentration of acrylonitrile throughout the electrolysis confirms that none is consumed. Thus, the extremely interesting results of Tanaka and Sato do not constitute an example of a relatively slow electrode reaction being catalyzed by an electrogenerated organometallic intermediate. [The reduction of $\mathrm{Co}(\mathrm{I})$ to $\mathrm{Co}(-\mathrm{I})$ is "catalyzed" by coordinated acrylonitrile but since the reduction does not lead to the same product in the absence and presence of acrylonitrile, the latter is not functioning as a true catalyst.]

That many vinyl monomers mimic the behavior of acrylonitrile (Table IV) despite having widely different electrochemistry of their own in the absence of Co (bipy) ${ }_{3}+$ adds support to the notion that one is dealing with a general type of coordination chemistry involving a low valent transition metal center and activated olefins as ligands. Ethylene and acetylene were without effect on the polarography of Co(bipy) ${ }_{3}{ }^{2+}$. Carbon monoxide appeared to react with $\mathrm{Co}$ (bipy) ${ }_{3}{ }^{+}$ and facilitate its further reduction but the reaction was not examined in detail.

Very recently we observed that electrogenerated $\mathrm{Co}$ (bipy) ${ }_{3}{ }^{+}$can function as an effective catalyst for the reductive dimerization of allyl halides to produce hexadienes in a reaction having many of the features Tanaka and Sato believed they had observed in the case of acrylonitrile. The details of these experiments will be described in a forthcoming publication. 


\section{Acknowledgments}

This work was supported by the National Science Foundation. Shlomo Margel gratefully acknowledges a Chaim Weizmann Fellowship.

Manuscript submitted July 12, 1977; revised manuscript received Sept. 19, 1977.

Any discussion of this paper will appear in a Discussion Section to be published in the December 1978 JourNaL. All discussions for the December 1978 Discussion Section should be submitted by Aug. 1, 1978.

Publication costs of this article were assisted by the California Institute of Technology.
REFERENCES

1. N. Tanaka and Y. Sato, Bull. Chem. Soc., Jpn., 41, 2059 (1968).

2. F. H. Burstail and R. S. Nyholm, J. Chem. Soc., 1952,3570

3. B. Martin, W. R. McWhinnie, and G. M. Waind, J. Inorg. Nucl. Chem., 23, 207 (1961).

4. A. A. Vloek, Nature, 180, 753 (1957).

5. Y. Kaizu, Y. Torii, and H. Kobayashi, Bull. Chem. Soc. Jpn., 43, 3296 (1970).

6. F. J. C. Rossotti and H. Rossotti, "The Determination of Stability Constants," p. 47, McGraw-Hill Book Co., New York (1961)

7. R. S. Nicholson and I. Shain, Anal. Chem., 36, 706 (1964).

\title{
Semiconductor Electrodes
}

\section{Electrochemistry and Electroluminescence at $n$-Type $\mathrm{TiO}_{2}$ in Aqueous Solutions}

\author{
Rommel N. Noufi,, Paul A. Kohl, " Steven N. Frank, ${ }^{* *}$ and Allen J. Bard** \\ Department of Chemistry, The University of Texas, Austin, Texas 78712
}

\begin{abstract}
The electrochemical behavior of single crystal $\mathrm{n}-\mathrm{TiO}_{2}$ was investigated in aqueous solutions. Charge transfer at the semiconductor/electrolyte interface was probed with several redox couples with standard redox potentials spanning a wide range. Most reductions occurred at potentials close to $V_{\mathrm{fb}}$, the flatband potential and the current-voltage behavior suggested involvement of surface states in the charge transfer process. Evidence for the adsorption of phosphate ion and its effect on the reduction of $\mathrm{Fe}(\mathrm{CN}) 6^{3-}$ is also presented. Electroluminescence was observed during reduction of $\mathrm{S}_{2} \mathrm{O}_{8}{ }^{2-}$ at wavelengths longer than $700 \mathrm{~nm}$, suggesting the existence of intermediate levels.
\end{abstract}

The electrochemical behavior of $\mathrm{n}-\mathrm{TiO}_{2}$ has been the subject of several recent investigations including a previous report in this series (1), which utilized an aprotic solvent, acetonitrile (ACN), and which postulated that electron transfer can occur via intermediate levels or surface states within the bandgap region. Studies in aqueous solutions with $\mathrm{TiO}_{2}$ (2) and other semiconductors $(3,4)$ have also investigated the mechanism of charge transfer of added redox couples at the semiconductor/solution interface. Although not as many Nernstian, one-electron redox couples are available in aqueous, as compared to nonaqueous solutions, the relative location of the energy levels of $\mathrm{TiO}_{2}$ at the semiconductor/solution interface (i.e., the flatband potential) can be changed in aqueous solutions by relatively large amounts by changing the solution $p H$. This provides another variable for investigating the band structure. This approach has previously been used to study $\mathrm{SiC}$ (4) and $\mathrm{SnO}_{2}(5)$.

In the present study the semiconductor/solution interface was investigated by several techniques. Electron transfer reactions of couples, including some with standard redox potential well positive of those used in a previous study (2), were investigated at different $p H$ 's. To probe the existence and role of intermediate levels within the bandgap, electroluminescence of the $n-\mathrm{TiO}_{2}$ semiconductor caused by electron-hole recombination from minority carrier injection from the electrolyte was studied. Hole injection into n-type semiconductors leading to radiative recombination has previously been demonstrated for $\mathrm{GaP}(6), \mathrm{SnO}_{2}, \mathrm{ZnO}$, CdS, and GaAs (7).

In addition a study of the space charge capacitance, $C_{\mathrm{sc}}$, as a function of potential, $E$, was undertaken in an

- Electrochemical Society Student Member.

Key words: semiconductors, luminescence, surface states. attempt to determine the donor density $\left(N_{\mathrm{D}}\right)$ and flatband potential $\left(V_{f b}\right)$, via the Schottky-Mott equation (Eq. [1]) (8)

$$
1 / C_{\mathrm{sc}^{2}}{ }^{2}=\left(\Delta \phi_{\mathrm{s}}-k T / e\right) 2 /\left(\epsilon \epsilon_{0} e N_{\mathrm{D}}\right)
$$

where $C_{\mathrm{sc}}$ is the space charge capacitance, $\Delta \phi_{\mathrm{s}}$ is the amount of band bending, $k$ is the Boltzmann constant, $T$ is the absolute temperature, $e$ is the electronic charge, $\epsilon$ is the dielectric constant of the semiconductor, and $\epsilon_{0}$ is the permittivity of free space. In several previous studies these plots of $C_{s c}-2$ vs. $E$ showed deviations from the behavior predicted by Eq. [1] [see, for example, $(2,9,10)$ and references therein]. In this work, two independent methods were used to calculate $N_{\mathrm{D}}$ for several $\mathrm{n}-\mathrm{TiO}_{2}$ crystals: (i) capacitance determined by a-c methods and cyclic voltammetry via Eq. [1] and (ii) conductance. Ohmic contacts were made by four different methods to determine their effect on the capacitance-potential behavior.

\section{Experimental}

The single crystal $\mathrm{n}-\mathrm{TiO}_{2}$ semiconductors used for the electrochemical investigation of redox couples were obtained from National Lead (Niagara Falls, New York). Two of the crystals were cut perpendicular to the $\mathrm{C}_{2}$ axis and one of these was heated to $650^{\circ} \mathrm{C}$ in vacuum at $10^{-4}$ Torr for $3 \mathrm{hr}$ and will be called "the moderately doped sample" with $N_{\mathrm{D}} \simeq 10^{18} / \mathrm{cm}^{3}$, as determined from a Schottky-Mott plot. The other was heated at $650^{\circ} \mathrm{C}$ in a hydrogen atmosphere for $15 \mathrm{~min}$ and will be denoted "the highly doped sample," with $N_{\mathrm{D}} \cong 10^{20} / \mathrm{cm}^{3}$. An ohmic contact was made to one side of each crystal by electrochemically depositing In from a $0.1 \mathrm{M} \mathrm{InCl} l_{3}$ solution.

The capacitance measurements were made with four crystals cut perpendicular to the $\mathrm{C}_{2}$ axis from a boule 